\title{
The Prevalence of Bi-Directional Intimate Partner Violence Reported by Portuguese
}

\section{Men}

Despite the widespread debate on gender asymmetry (e.g., Dobash \& Dobash, 2004;

Hines \& Douglas, 2010; Johnson, 1995; Straus, 2010), it is now widely recognized that both men and women can be perpetrators and victims of IPV (e.g., Capaldi, Shortt, Kim, Wilson, Crosby, \& Tucci, 2009; Dardis, Dixon, Edwards, \& Turchik, 2015; Tillyer \& Wright, 2014; Zverina, Stam, \& Babins-Wagner, 2011). Controversy still exists regarding the relative proportions of violence suffered and perpetrated by men and by women. For example, when studies focus on crime statistics, women form the majority of victims (e.g., Brogden \& Nijhar, 2004; RASI, 2017). However, international studies (e.g., Lövestad \& Krantz, 2012; Randle \& Graham, 2011) with community samples have found that men experience significant levels of IPV (e.g., Archer, 2000; Beel, 2013; Hines \& Douglas, 2011; Lövestad \& Krantz, 2012; Machado \& Matos, 2012; Machado \& Matos, 2014). In the US, community samples with adults in heterosexual relationships have shown that $25 \%$ to $50 \%$ of victims are male (Hines \& Douglas, 2011). The National Intimate Partner and Sexual Violence Survey (Breiding, Chen, \& Black, 2014) found that more than 1 in 4 men $(28.5 \%)$ in the US have experienced rape, physical violence, and/or stalking by an intimate partner in their lifetime. A review by Desmarais, Reeves, Nicholls, Telford, and Fiebert (2012) explored a decade's worth of research on IPV in heterosexual relationships. Based on data from 91 studies, they estimated that approximately 1 in 4 women $(23.1 \%)$ and 1 in 5 men $(19.3 \%)$ had experienced physical violence in an intimate relationship (Desmarais et al., 2012). European studies have also found this pattern of prevalence rates for men and women (e.g., Lövestad \& Krantz, 2012; Costa et al., 2015). In Portugal, there are no national annual surveys on IPV. The only Portuguese survey to date that included men was completed in 2007 with a sample of 1000 women and 1000 men and found that $6.4 \%$ of women and $2.3 \%$ of men were victims of IPV 
(Lisboa, Barroso, Patrício, \& Leandro, 2009). In Portugal, the data on male victims are from a clinical sample of all observed cases in the North Branch of the Institute of Forensic Medicine, which found that men constituted $11.5 \%$ of the victims of IPV (Carmo, Grams, \& Magalhães, 2011), and from the most widely known non-governmental agency in the country, the Portuguese Association for Victim Support (APAV, 2015). This organization reportedly helped a total of 1,240 adult men who were victims of domestic violence between 2013 and 2015, an increase of 14.4\% from previous years (APAV, 2015). Moreover, since 2000, when only 255 men sought help from this agency, there has been a large increase in the number of men seeking help for intimate abuse.

Considering the widespread debate regarding the identity of the victim and the perpetrator, it is important to highlight that several international studies have demonstrated that most IPV is mutual or bidirectional (e.g., Capaldi et al., 2009; Capaldi, Knoble, Shortt, \& Kim, 2012; Esquivel-Santoveña, Lambert, \& Hamel, 2013; Krahé, Bieneck, \& Möller, 2005). A systematic review by Langhinrichsen-Rohling, Misra, Selwyn and Rohling (2012a) found that rates of bidirectional IPV ranged from $39 \%$ (military or male treatment samples) to $72 \%$ (female-oriented samples), with more than half of all population, community and student samples demonstrating bidirectional IPV. In a European study, men and women experienced IPV as both victims and perpetrators (Costa et al., 2015). This pattern continues to be found in more recent surveys (e.g., Esquivel-Santoveña, Lambert, \& Hamel, 2013; Hellemans, Buysse, De Smet, \& Wietzker, 2014; Tillyer \& Wright, 2014). The annotated bibliography by Fiebert (2014) describes 343 scholarly investigations (270 empirical studies and 73 reviews) demonstrating that women are as physically aggressive as men (or more) in their relationships with their spouses or opposite-sex partners. In relation to this and at an international level, women are gradually being arrested and prosecuted as perpetrators of IPV (e.g., Henning \& Feder, 2004; Henning, Jones, \& Holdford, 2005; Henning, Martinsson, \& 
Holdford, 2009). However, some of these studies have revealed that while IPV perpetrated by dually arrested couples is technically bidirectional, many aspects of such bidirectional violence are gender asymmetric, including measures of overall physical abuse, the issuing of lethal threats, injuries inflicted, prior IPV arrests and the risk of recidivism (e.g., Henning et al., 2005; Henning et al., 2009). In Portugal, there are no empirical data on the phenomenon of mutual abuse in intimate relationships. However, the official crime statistics suggest that in recent years, there is a small but growing tendency to report intimate abuse incidents through dual presentations of charges; that is, in recent years, criminal complaints of mutual IPV have increased (Matos \& Santos, 2014).

The current study is the first cross-sectional research conducted in Portugal to explore IPV based on a population that is not well studied (i.e., male victims) and to examine the prevalence of IPV victimization and perpetration as well as the overlap of these roles and the types of violence reported. For this purpose, IPV, as defined by Portuguese law, is considered the act of inflicting any physical or mental injury, "including body punishments, deprivation of freedom and sexual offenses, against those who cohabit or not with the perpetrator and/or maintain an intimate relationship" (Law No. 59/2007 of 4 September). In Portugal, even though domestic violence has been considered a public crime since 2000 and Portuguese law is gender neutral (Penal Code, 2014), the phenomenon of IPV against men remains an underdeveloped research area, and attention from the media and the political and judiciary systems is almost non-existent.

This study represents one of the few studies within the international literature to explore the differences in the types of IPV suffered and perpetrated by men in which men are divided into victims only, perpetrators only or both the victim and the perpetrator. Usually, only the victimization or perpetration of IPV is studied. Men's accounts of IPV remain largely overlooked across the European Union (EU) and in Portugal in particular. Indeed, 
policy and practice in Western nations seems to still be shaped by a gendered approach to IPV, which is associated with feminist analyses (i.e., a perspective that focuses on women as victims; e.g., Bates, Graham-Kevan, \& Archer, 2014; Bates \& Graham-Kevan, 2016). This approach has been useful but is insufficient. In Portugal, even though IPV law is neutral and IPV has been considered a political and social priority area (e.g., Commission for Citizenship and Gender Equality, 2015), studies have revealed that Portugal, similar to other Western nations, does not appear to be prepared to address men in a role other than perpetrators of IPV. For instance, only the last national plan against Domestic Violence ${ }^{1}(2013-2017)$ adopted inclusive language regarding men and women as victims and as perpetrators. Prior to this last national plan, when addressing perpetrators, the plans referred only to men. Moreover, male victims who have sought formal help have negatively evaluated the services provided by the national support system, complaining that they experienced genderstereotyped treatment and different criteria from professionals and services (Machado, Santos, Graham-Kevan, \& Matos, 2016). Therefore, the research aims of this study, with regard to both in the past year and across the lifetime, are to 1) map the prevalence of victimization, perpetration, and victimization-perpetration situations reported by a sample of males; 2) explore the differences in the types of violence between victimization and perpetration; 3) explore the differences between the categories (victims vs. victimsperpetrators; perpetrators vs. victims-perpetrators) in terms of the types of violence suffered/perpetrated.

\section{Method}

\section{Sample}

\footnotetext{
${ }^{1}$ Domestic Violence (DV) is the term used, but in this paper we adopted the term IPV once that DV encompasses behaviours of IPV.
} 
The sample consisted of 1556 men, whose age ranged from 18 to 78 years $(M=32.58$, $S D=10.19)$. The majority of the participants were Portuguese and currently single or married/cohabiting; of the $27.6 \%$ of the participants with children, the mean number of children was $1.7(S D=.80)$. The majority of participants were employed, lived in an urban area, were in the upper middle class and had higher education qualifications. With regard to exposure to family violence while growing up (i.e., all types of domestic violence), most participants reported that they had never witnessed any type of IPV between their parents $(84.3 \%)$ or been a victim of any type of violence within the home (90.6\%). See Table 1 for further information about the sample characteristics.

\section{Procedures}

This study was conducted online, at a national level, with a convenience and nonrandom sample comprising adult heterosexual men aged 18 years or older who had a dating history of at least one intimate heterosexual relationship that lasted for more than one month. Potential participants were invited to participate in a study about their intimate relationships and were recruited via e-mails advertising the study that were sent to formal contacts (e.g., municipal and local councils, universities, companies) and posts on social networking websites (e.g., Facebook). Men who decided to participate were directed to the study website to complete the measures. Participation in this study was anonymous, and no incentives were provided for participation. The Portuguese Data Protection Authority (CNPD), an independent national agency, approved this study.

\section{Instruments}

We describe the instruments used below. All questions were asked in Portuguese. Demographics. The men were asked for basic demographic information regarding age, nationality, current marital status, level of education, occupation, socioeconomic status, housing location and family history of direct and indirect violence. 
Revised Conflict Tactics Scale (CTS2; Straus, Hamby, Boney-McCoy, \& Sugarman, 1996; adapted by Paiva \& Figueiredo, 2006). This self-report instrument assesses how couples solve their conflicts. It contains five scales - negotiation, psychological aggression, sexual coercion, physical assault, and injury - with 39 pairs of items that relate to negotiation and aggression in terms of perpetration and victimization, for a total of 78 items. All subscales except negotiation can be further subdivided into minor and severe subscales using criteria outlined by the instrument's authors. Therefore, each scale contains both minor (e.g., being slapped, grabbed, pushed, or shoved; having a small cut or bruise; insisting on sex when the partner does not want to; insulting / swearing, shouting / yelling) and severe (e.g., being punched, kicked, burned, or beat up; broken bone, passing out; using force to make partner have sex; threatening to harm partner; intentionally destroying something belonging to partner) acts of IPV. Responses are provided on an eight-point scale (i.e., $1=$ once in the last year; $2=$ twice in the last year; $3=3-5$ times in the last year; $4=6-10$ times in the last year; $5=11-20$ times in the last year; $6=$ more than 20 times in the last year; $7=$ not in the last year but has occurred previously; and $8=$ never occurred) separately for victimization and perpetration. For the present study, the prevalence variable was transformed into a $0-1$ dichotomy, with a score of 1 assigned if one or more of the acts in the scale occurred. Prevalence rates were calculated for the previous year (i.e., scores of 1-6 on the items composing that scale) and across the lifetime (i.e., scores of 1-7 on the items composing that scale) using the criteria for the psychological aggression, sexual coercion, physical assault, and injury subscales. In this study, all subscales of violence and its minor and severe subscales were calculated, with the exception of negotiation strategies because these are not a form of aggressive victimization/perpetration. The subscales are the sum of the number of behaviours reported by the participants. The CTS2 has demonstrated good construct and discriminant validity and good reliability (e.g., Straus et al., 1996). Internal consistency and 
reliability statistics for the current sample were .76 (sexual aggression), .87 (psychological aggression), .93 (physical aggression) and .95 (injury).

\section{Data analysis}

The prevalence rates of victimization and perpetration and of types of violence were calculated for the past year and across the lifetime. To explore the differences between victimization and perpetration in the types of violence reported, $t$ tests were performed. Additionally, to explore the differences between the categories in terms of the types of violence suffered and perpetrated, participants were categorized into four categories: (1) victim only (i.e., individuals who reported victimization and no perpetration) (2.7\%); (2) perpetrator only (i.e., individuals who reported only perpetration) $(3.9 \%)$; (3) victim and perpetrator (i.e., individuals who reported being victims and perpetrators of aggressive behaviours) (73.7\%); and (4) no violence (reference category; individuals who did not report any aggressive victimization or perpetration) (19.7\%). To compare victims vs. victimsperpetrators and perpetrators vs. victims-perpetrators in terms of the types of violence suffered and perpetrated, $t$ tests were performed. Finally, association tests (e.g., chi-square) and regressions were used to compare/predict prevalence by demographics/socio-economics as independent variables. SPSS was used for analysis.

\section{Results}

\section{Prevalence rates}

Past Year vs. Lifetime. The past year prevalence rate of any IPV victimization was $69.7 \%$, and the perpetration rate was $70.6 \%$. The lifetime prevalence rate of any IPV victimization was $76.5 \%$, and the lifetime prevalence rate of any IPV perpetration was $77.6 \%$.

\section{Types of violence}

Past Year vs. Lifetime. In terms of the types of IPV, with respect to psychological aggression, $59.8 \%$ of the participants reported having been victims in the past year and $60.3 \%$ 
were perpetrators. Conversely, during the lifetime, $66.8 \%$ of the men were victims of IPV and $67.5 \%$ reported being perpetrators. For sexual coercion, in the past year, $30.6 \%$ were victims and $38.2 \%$ were perpetrators. Over their lifetime, $35.2 \%$ of the men had been sexually coerced and $43.8 \%$ had sexually coerced their partner. With respect to physical assault, in the past year, $16.2 \%$ had been physically assaulted and $13.5 \%$ reported physically assaulting a partner. During their lifetime, $20.4 \%$ of men were victims and $16.8 \%$ were perpetrators. Finally, on the injury sub-scale, $3.2 \%$ reported suffering an injury from a partner and $3 \%$ were perpetrators. During their lifetime, $4 \%$ of men were injured and 3.8\% reported injuring their partner.

Differences between the Types of Violence. Statistically significant differences were found in the types of violence between victimization and perpetration, both across the lifetime and in the past year. Men were significantly more likely to report perpetrating rather than being the victim of sexually coercive IPV, both in their lifetime $(t(1555)=11.44, p<.001 ; M=$ 0.52 for victimization vs. $M=0.72$ for perpetration, $S D s=1.00$ and 1.12 , respectively) and in the past year $(t(1555)=10.59, p<.001 ; M=.44$ for victimization vs. $M=.62$ for perpetration, $S D s=.93$ and 1.04, respectively). However, men reported more physical violence victimization than perpetration, both across their lifetime $(t(1555)=-6.05, p<.001$; $M=0.52$ for victimization vs. $M=0.40$ for perpetration, $S D s=1.63$ and 1.48 , respectively); and in the past year $(t(1555)=-5.09, p<.001 ; M=.40$ for victimization vs. $M=.31$ for perpetration, $S D s=1.47$ and 1.33 , respectively). Furthermore, there was a significant association between being a victim and being a perpetrator, $\chi^{2}(1)=1025,74, p<.001$.

\section{Victims, Perpetrators, and Victim-Perpetrator Overlap}

Differences between victims, perpetrators and victim-perpetrator overlap according to the types of violence suffered and perpetrated in the last year and lifetime. The results (see Table 2) document that the victim-perpetrator overlap category reported higher mean 
rates of all types of violence in their lifetime and in the past year when compared to the victim category. The results revealed that for both the lifetime and the past year, the victim category reported more victimization of psychological violence than the perpetrator category.

\section{Differences between the victim-perpetrator overlap category according to the types of} violence suffered and perpetrated for both the last year and lifetime. The differences between the level of victimization and perpetration for those in the victim and perpetrator categories were analysed (lifetime and last year) by the subscales of the CTS2. As shown in Table 3, across the lifetime and in the past year, men who were involved in bidirectional violence were more likely to be victims of physical assault and injury and perpetrators of sexual coercion. Additionally, regarding the sub-scales of minor and severe violence, those in the victim-perpetrator category more frequently reported being victims of minor and severe physical assault and of minor injury and were more likely to be perpetrators of minor sexual coercion. Across the lifetime, men who were involved in bidirectional violence were more likely to be victims of physical assault and perpetrators of sexual coercion. Additionally, regarding the sub-scales of minor and severe violence, those in the victim-perpetrator category more frequently reported being victims of minor and severe physical assault and were more likely to be perpetrators of minor sexual coercion. There were no other significant differences between victimization and perpetration.

\section{Discussion}

This is one of the few known studies to examine IPV based on a population that is not well studied, Portuguese men. This paper provides information on victimization, perpetration and the victimization and perpetration overlap, both across the lifetime and in the past year.

The main findings of this study revealed the following: 1) there is considerable overlap in IPV victimization and perpetration (i.e., men reported that they were victims and perpetrators at similar rates); 2) bidirectional violence is the most common dynamic of IPV; 
and 3) there was asymmetry in the types of violence and in the subscales of minor and severe violence. These findings reinforce the understanding of IPV as a complex and heterogeneous phenomenon with numerous distinctive facets (e.g., Winstok \& Straus, 2014).

In the current study, the similar rates of global victimization and perpetration are consistent with previous research and are consistent with Portuguese definitions of IPV that do not require injury or repeated incidents to be considered a crime. Hence, an "act-based" approach is appropriate in this context (e.g., Archer, 2000; Dobash \& Dobash, 2004).

When exploring the different types of IPV, several authors have reported the existence of differences in the perpetration of IPV because the types of aggression used by both sexes differ: women are responsible for less severe violence, and sexual violence is mainly attributed to men (e.g., Anderson, 2002; Dobash \& Dobash, 2004; Saunders, 2002; Tjaden \& Thoennes, 2000). However, it is important to note that these data are not consistent (see, for example, Costa et al., 2015). In the present study, these differences in the types of violence reported by men, whether victims or perpetrators, were only partially observed. We found that men reported higher rates of perpetration (vs. victimization) of sexual coercion both across the lifetime and in the past year, and this type of violence was highest in the victim and perpetrator category, which is consistent with previous research (e.g., Coker et al., 2002; Costa et al., 2015; Lövestad \& Krantz, 2012). However, this finding did not hold for physical IPV, for which men were more likely to report being victims than perpetrators across the lifetime and in the past year. The highest rates of physical IPV occurred in the victim and perpetrator category, which challenges the dominant frameworks used to interpret IPV (i.e., IPV is a "women's issue" and arises predominantly from assaults by male perpetrators on female victims; e.g., Fergusson, Horwood, \& Ridder, 2005). This framework was also challenged by the finding that men reported more victimization of severe physical violence. Considering these results and the review of the literature, it seems important for public 
policies and measures to combat IPV (i.e., prevention and intervention) to adopt a more gender-neutral approach and an ecological analysis to understand and guide IPV research and practice and to address the experiences and needs of all possible victims and perpetrators (e.g., McCarrick, McCabe, \& Hirst-Winthrop, 2015; Swan, Gambone, Caldwell, Sullivan, \& Snow, 2008).

Nevertheless, the data revealed that most of the violence was bidirectional, which is consistent with the literature on community samples (e.g., Capaldi et al., 2009; Capaldi et al., 2012; Esquivel-Santoveña et al., 2013; Langhinrichsen-Rohling et al., 2012a). The high rate of overlap reported by this sample of Portuguese men also demonstrates the complexity of this phenomenon (e.g., different sampling and survey methods can influence the findings regarding prevalence rates; see, for example, Archer, 2000 and Krahé et al., 2005, for more information) and challenge the prevailing paradigm of victimology (i.e., the dichotomous reading of the role of victim or perpetrator). The overall data of this study and other studies (e.g., Capaldi et al., 2009; Capaldi et al., 2012; Esquivel-Santoveña et al., 2013; Langhinrichsen-Rohling et al., 2012a) have revealed that these positions are not always mutually exclusive. To effectively respond to a phenomenon as complex as IPV, like other authors (e.g., Dixon \& Graham-Kevan, 2011), we believe that Europe (in particular, Portugal) could benefit from adopting a wider theoretical perspective that includes, for example, samesex violence, female-to-male violence or reciprocal IPV. Nevertheless, it is important to note that in this study, the context of violence is unknown; thus, it is not possible to identify how and why the violence occurred. The importance of the context of violent behaviour was highlighted by the typology of Johnson (1995). Therefore, the percentage of dual involvement or overlap found in this study could represent situational couple violence, violent resistance or mutual violent control. Future studies should investigate these elements of couples to understand the real extent of such violence and its context and dynamics. 
Moreover, it is important to understand whether these roles evolve during the relationship (i.e., if one partner starts as victim and evolves to become a perpetrator and vice versa). Additionally, some studies have revealed that even in cases where IPV is bidirectional, many aspects of such bidirectional violence are gender-asymmetric, including physical abuse, lethal threats, injuries, prior IPV arrests or risk of recidivism. In the present study, differences were not found in the IPV measure used to capture physical abuse and injuries inflicted; however, the other variables were not included. Future studies could examine a mixed sample and focus on variables such as lethal threats, prior IPV arrests or the risk of recidivism to explore gender (a)symmetry.

Finally, the stereotype that IPV only occurs in more disadvantaged social layers dominated by poverty and low education (e.g., Casique \& Furegato, 2006) is challenged by the sociodemographic data of this study, in which many participants had high levels of education and a higher average socioeconomic status. In addition, IPV seems to not be exclusive to married couples.

Although the results of this study provide a contribution to the field, they should be interpreted carefully with consideration of the study's many limitations. Specifically, these findings are based on the reports of only one member of the couple and on self-report data (e.g., participants may under-report perpetration or overstate their victimization) and crosssectional data. Future research should examine the IPV victim-perpetrator overlap in partner samples, adopt complementary self-report measures, and use longitudinal designs. These three conditions could help to clarify the causal directions of our findings, the extent of IPV, its contexts, motives and impacts, and the relational processes by which intimate relationships change over time. Another variable that would have enriched our study is the inclusion of a measure of fear and of coercion. Several studies report fear as a consequence that should be 
included when analysing IPV and coercion as a behaviour to which women report greater exposure.

Furthermore, online data collection was used in the current study, which is considered a useful way of examining the psycho-social aspects of socially negative behaviours (e.g., gambling; Wood \& Griffiths, 2007). The online participation method is likely to be effective in reducing the fear and social disapproval experienced by men involved in IPV as the anonymity of the computer may increase their disclosure (e.g., Rhodes, Lauderdale, He, Howes, \& Levinson, 2002; Tsui, 2014). Although there are disadvantages to this method (e.g., potentially biased sample, validity issues), they are similar to more conventional research techniques. In the current study, the use of an online data collection method may have influenced the results by restricting the sample to men who had access to the Internet, saw the advertisement for the study and were willing to participate without compensation. This approach may explain the homogeneity of the sample in terms of its demographics (e.g., age, socioeconomic status, educational level, nationality). Therefore, the results may not be generalizable to a wider Portuguese population, and future studies should endeavour to recruit a more diverse population. Lastly, the instrument used in the data collection is not without criticism. The CTS is the most widely used measure of IPV but is also the most criticized (Straus, 2012). One of the primary reasons this measure has received such attention from critics is that when it is used, it generally finds "gender symmetry" in the perpetration of IPV (e.g., Archer, 2000; Fiebert, 2014; Hamby, 2016; Lehrner \& Allen, 2014), even in agency- and clinical-level violence cases (e.g., Moffitt, Caspi, Rutter, \& Silva, 2001). These findings appear inconsistent with studies using data from criminal justice or medical sources and have led to criticism from feminist (and other) researchers, who have sought to negate the CTS findings by criticizing the methodology. The CTS has been argued to be unreliable and invalid because "confining self-report data to a checklist of acts, devoid of motives, meanings 
and consequences cannot insure objectivity, validity or an adequate development of theory to explain violence" (Dobash, Dobash, Wilson, \& Daly, 1992, p.71). Major criticisms have centred on the perceived inability of the CTS to take into account the different consequences of IPV for males and females as well the context of bidirectional violence (e.g., whether violence was in self-defence) (Lehrner \& Allen, 2014; Morse, 1995). A further criticism is that failing to measure injuries obscures the unequal impact of IPV in terms of injuries sustained by men and women. Straus $(2012 ; 1999)$ has gone to some lengths to address these criticisms both theoretically and empirically (e.g., Straus et al., 1996), and a major revision to the CTS (CTS2, Straus et al., 1996) was made in response to these issues. The CTS2 includes additional scales to measure injury and sexual coercion, although motivation (e.g., selfdefence or coercive control) is still not included. Although the CTS2 does not measure motivation or the context of IPV, this issue in itself is not a shortcoming. All measures are necessarily constrained and should be used in conjunction with other measures that allow research questions to be answered. For example, to explore potential sex differences in motivations for IPV, researchers should ask additional questions and/or include additional scales. Recent systematic reviews show the utility of such an approach (e.g., motivations, Langhinrichsen-Rohling, McCullars, \& Misra, 2012b; coercive control, Carney \& Barner, 2012; impact, Lawrence, Oringo, \& Brock, 2012).

Finally, it is important to highlight that this study presents data from an underresearched population of Portuguese men and finds patterns consistent with research from other nationalities. This study has social implications, such as alerting and reporting on a lesser-known and under-studied reality: men as victims of female violence in intimate relationships. The findings contribute to the demystification of different beliefs, such as the widespread idea that women are the victims and men are the perpetrators of IPV in mutually exclusive roles. In addition, victim and perpetrator status for IPV presents challenges for 
those working in this field. Public services, domestic violence agencies, police, courts, and other service providers should be alerted to the factors that intensify both the victimization and the perpetration of IPV and, when possible, should reduce or respond to these risk factors (e.g., Tyler \& Wright, 2014). Furthermore, it is important to conceptualize all the facets and complexities of IPV (e.g., Dixon \& Graham-Kevan, 2011) when designing public policies to combat this phenomenon. 
Table 1

Demographic characteristics

$$
\text { n }(\%)
$$

Nationality

Portuguese

$1523(97.9)$

Other

$33(2.1)$

Current marital status

Single

$931(59.8)$

Married/Cohabiting

$622(40)$

Widowed

$3(0.2)$

Occupational status

Employed

$1006(64.7)$

Student

$358(23)$

Unemployed

$155(10)$

Retired

$37(2.4)$

Socioeconomic status

Lower

$361(23.2)$

Lower middle

$5(0.3)$

Middle

$129(8.3)$

Upper middle

$890(57.2)$

Upper

$171(11)$

Educational qualifications

Fourth year or less

$61(3.9)$

High school

$318(20.4)$

Bachelor's degree

$148(9.5)$ 
Higher education (Master's, PhD)

$1029(66.2)$

Housing location

Countryside

$359(23.1)$

Urban area

$1197(76.9)$

Family history

Direct victim

Yes

$9.4 \%$

No

$90.6 \%$

Indirect victim

Yes

$15.7 \%$

No

$84.3 \%$ 
Table 2. Differences between victims, perpetrators and victim-perpetrator overlap according to the types of violence suffered and perpetrated in the last year and lifetime

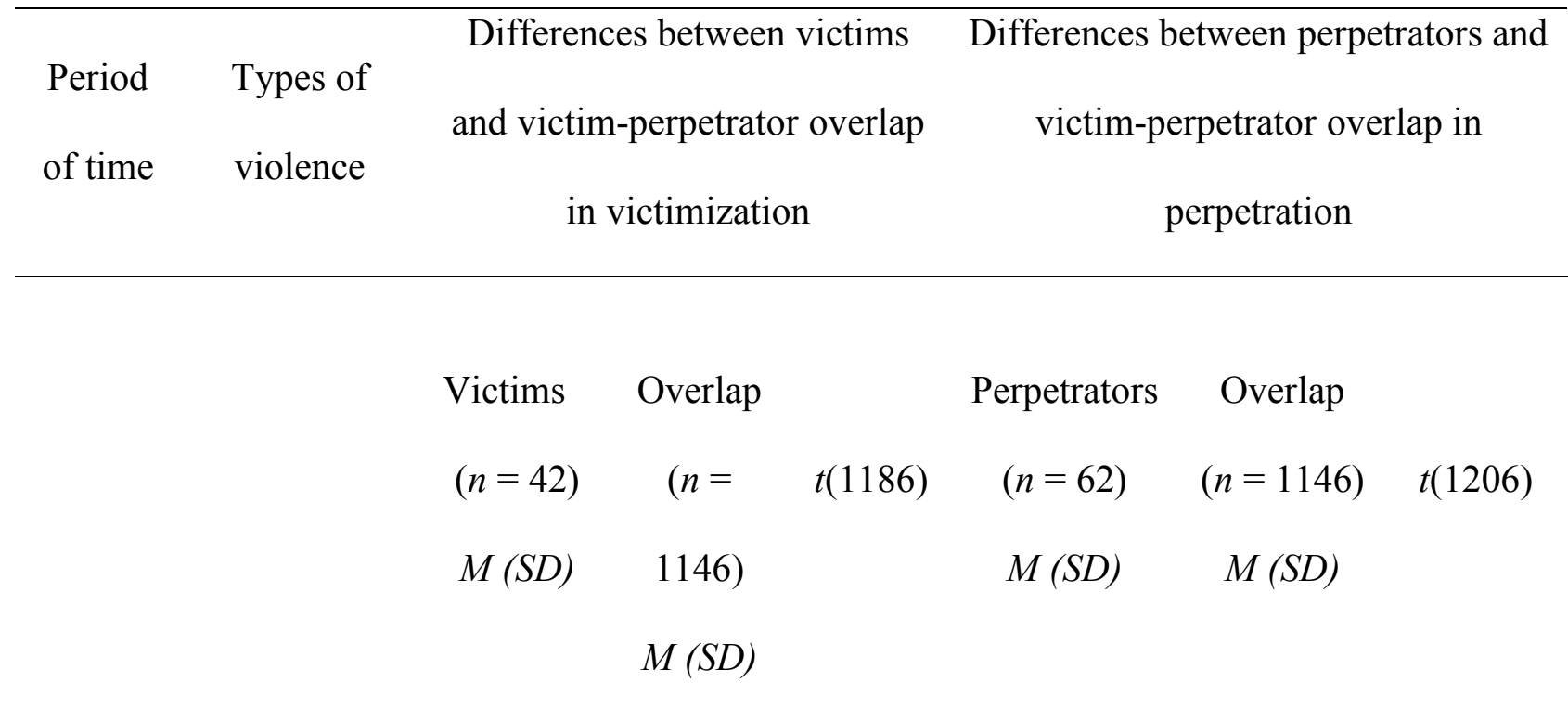

\begin{tabular}{|c|c|c|c|c|c|c|c|}
\hline & Psychological & $1.00(1.10)$ & $2.01(1.73)$ & $-5.68 * * *$ & $0.63(1.01)$ & $2.34(1.70)$ & $-9.70 * * *$ \\
\hline Last & Sexual & $0.26(0.50)$ & $0.59(1.04)$ & $-4.01 * * *$ & $0.66(1.10)$ & $0.80(1.12)$ & -0.99 \\
\hline \multirow[t]{2}{*}{ year } & Physical & $0.19(0.46)$ & $0.54(1.68)$ & $-4.04 * * *$ & $0.27(1.55)$ & $0.40(1.50)$ & -0.64 \\
\hline & Injury & $0(0)$ & $0.12(0.72)$ & $-5.60 * * *$ & $0.10(0.76)$ & $0.10(0.68)$ & -0.80 \\
\hline \multirow{4}{*}{ Lifetime } & Psychological & $1.19(1.04)$ & $2.37(1.74)$ & $-6.97 * * *$ & $0.73(1.00)$ & $2.34(1.70)$ & $-11.84 * * *$ \\
\hline & Sexual & $0.31(0.52)$ & $0.70(1.11)$ & $-4.51 * * *$ & $0.76(1.10)$ & $0.94(1.19)$ & -1.28 \\
\hline & Physical & $0.24(0.53)$ & $0.69(1.87)$ & $-4.61 * * *$ & $0.29(1.55)$ & $0.52(1.67)$ & -1.14 \\
\hline & Injury & $0.00(0.00)$ & $0.15(0.80)$ & $-6.30 * * *$ & $0.11(0.77)$ & $0.13(0.76)$ & -0.21 \\
\hline
\end{tabular}

$* p<.05 ; * * p<.01 ; * * * p<.001$ 
Table 3. Differences between the victim-perpetrator overlap category according to the types of violence suffered and perpetrated in the last year and lifetime

\begin{tabular}{|c|c|c|c|c|}
\hline \multirow{4}{*}{$\begin{array}{l}\text { Period } \\
\text { of time }\end{array}$} & \multirow{4}{*}{ Types of violence } & \multicolumn{3}{|c|}{$\begin{array}{l}\text { Overlap: Differences between victimization and } \\
\text { perpetration }\end{array}$} \\
\hline & & Victimization & Perpetration & \\
\hline & & $(n=1146)$ & $(n=1146)$ & $t(1145)$ \\
\hline & & $M(S D)$ & $M(S D)$ & \\
\hline \multirow{12}{*}{ Last year } & Psychological & $2.01(1.73)$ & $1.96(1.67)$ & -1.67 \\
\hline & Minor & $1.71(1.31)$ & $1.69(1.30)$ & 0.90 \\
\hline & Severe & $0.30(0.71)$ & $0.28(0.66)$ & 1.73 \\
\hline & Sexual & $0.59(1.04)$ & $0.80(1.12)$ & $10.40 * * *$ \\
\hline & Minor & $0.53(0.75)$ & $0.75(0.91)$ & $-11.91 * * *$ \\
\hline & Severe & $0.06(0.47)$ & $0.06(0.45)$ & 1.48 \\
\hline & Physical & $0.54(1.68)$ & $0.40(1.50)$ & $-6.07 * * *$ \\
\hline & Minor & $0.39(0.98)$ & $0.30(0.82)$ & $5.90 * * *$ \\
\hline & Severe & $0.15(0.86)$ & $0.11(0.80)$ & $4.04 * * *$ \\
\hline & Injury & $0.12(0.72)$ & $0.10(0.68)$ & $-2.00^{*}$ \\
\hline & Minor & $0.06(0.32)$ & $0.05(0.28)$ & $2.03 *$ \\
\hline & Severe & $0.05(0.45)$ & $0.05(0.44)$ & 0.73 \\
\hline \multirow{4}{*}{ Lifetime } & Psychological & $2.37(1.74)$ & $2.34(1.70)$ & 1.13 \\
\hline & Minor & $1.99(1.28)$ & $1.98(1.26)$ & 0.33 \\
\hline & Severe & $0.38(0.78)$ & $0.35(0.74)$ & 1.52 \\
\hline & Sexual & $0.70(1.11)$ & $0.94(1.19)$ & $-11.21 * * *$ \\
\hline
\end{tabular}




\begin{tabular}{rccc} 
Minor & $0.62(0.79)$ & $0.87(0.94)$ & $-12.84 * * *$ \\
Severe & $0.08(0.52)$ & $0.07(0.49)$ & 1.34 \\
Physical & $0.69(1.87)$ & $0.52(1.67)$ & $6.97 * * *$ \\
Minor & $0.51(1.11)$ & $0.38(0.93)$ & $6.87 * * *$ \\
Severe & $0.18(0.94)$ & $0.14(0.88)$ & $4.29 * * *$ \\
Injury & $0.15(0.80)$ & $0.13(0.76)$ & 1.67 \\
Minor & $0.08(0.35)$ & $0.07(0.33)$ & 1.72 \\
Severe & $0.07(0.51)$ & $0.07(0.49)$ & 0.58 \\
\hline$* p<.05 ; * * p<.01 ; * * *<<.001$ & & & \\
\hline
\end{tabular}




\section{References}

Archer, J. (2000). Sex differences in aggression between heterosexual partners: A metaanalytic review. Psychological Bulletin, 126, 651-680. doi: 10.1037//00332909.126.5.65

Anderson, K. (2002). Perpetrator or victim? Relationships between intimate partner violence and well-being. Journal of Marriage and the Family, 6, 851-863. doi: 10.1111/j.17413737.2002.00851.X

APAV (Portuguese Association for Victim Support; 2015). Relatório Anual 2014 [Annual report 2014]. Retrieved from http://apav.pt/apav_v2/images/pdf/Estatisticas_APAV_Relatorio_Anual_2014.pdf

Bates, E., \& Graham-Kevan, N. (2016). Is the presence of control related to help-seeking behaviors? A test of Johnson's assumptions regarding sex differences and the role of control in intimate partner violence. Partner Abuse, 7, 3-25. doi: 10.1891/19466560.7 .1 .3

Bates, E., Graham-Kevan, N., \& Archer, J. (2014). Testing predictions from the male control theory of men's partner violence. Aggressive Behavior, 40, 42-55. doi: $10.1002 / a b .21499$

Beel, N. (2013). Domestic violence, gender, and counselling: Toward a more genderinclusive understanding. Psychotherapy in Australia, 19(4), 44-52. Retrieved from http://www.psychotherapy.com.au/fileadmin/site_files/journal/articles/August_2013_ Beel.pdf

Breiding, M., Chen, J., \& Black, M. (2014). Intimate partner volence in the United States 2010. Atlanta, GA: National Center for Injury Prevention and Control, Centers for Disease Control and Prevention. Retrieved from 
http://www.cdc.gov/violenceprevention/pdf/cdc_nisvs_ipv_report_2013_v17_single_a. pdf

Brogden, M., \& Nijhar, S. (2004). Abuse of adult males in intimate partner relationships in Northern Ireland. Belfast, Northern Ireland: Office of the First Minister and Deputy First Minister of the Northern Ireland Assembly. Retrieved from http://www.ofmdfmni.gov.uk/index/equality/equalityresearch/researchpublications/relationships.pdf

Capaldi, D. Shortt, J., Kim, H., Wilson, J., Crosby, L., \& Tucci, S. (2009). Official incidents of domestic violence: Types, injury, and associations with nonofficial couple aggression. Violence and Victims, 24, 502-519. doi: 10.1891/0886-6708.24.4.502

Capaldi, D., Knoble, N., Shortt, J., \& Kim, H. (2012). A systematic review of risk factors for intimate partner violence. Partner Abuse, 3, 231-280. doi: 10.1891/19466560.3.2.231.

Carmo, R., Grams, A., \& Magalhães, T. (2011). Men as victims of intimate partner violence. Journal of Forensic and Legal Medicine, 18, 355-359. doi: 10.1016/j.jflm.2011.07.006

Carney, M., \& Barner, J. (2012). Prevalence of partner abuse: Rates of emotional abuse and control. Partner Abuse, 3, 286-335. doi: 10.1891/1946-6560.3.3.286

Casique, L., \& Furegato, A. (2006). Violência contra mulheres: Reflexões teóricas [Violence against women: Theoretical reflections]. Revista Latino-Americana de Enfermagem, 14, 950-956. doi: 10.1590/S0104-11692006000600018

Commission for Citizenship and Gender Equality. (2015). National Plans. Presidency of the Council of Ministers. Retrieved from https://www.cig.gov.pt/planos-nacionaisareas/violencia-domestica/ 
Coker, A., Davis, K., Arias, I., Desai, S., Sanderson, M., Brandt, H., \& Smith, P. (2002). Physical and mental health effects of intimate partner violence for men and women. American Journal of Preventive Medicine, 23, 260-268. doi: 10.1016/S07493797(02)00514-7

Costa, D., Soares, J., Lindert, J., Hatzidimitriadou, E., Sundin, O., Toth, O., IoannidiKapolou, E., \& Barros, H. (2015). Intimate partner violence: A study in men and women from six European countries. International Journal of Public Health, 60, 467478. doi: 10.1007/s00038-015-0663-1

Dardis, C., Dixon, K., Edwards, K., \& Turchik, J. (2015). An examination of the factors related to dating violence perpetration among young men and women and associated theoretical explanations: A review of the literature. Trauma, Violence, \& Abuse, 16, 136-152. doi: $10.1177 / 1524838013517559$

Desmarais, S., Reeves, K., Nicholls, T., Telford, R., \& Fiebert, M. (2012). Prevalence of physical violence in intimate relationships, part 1: Rates of male and female vitimization. Partner abuse, 3, 140-169. doi: 10.1891/1946-6560.3.2.140

Dixon, L., \& Graham-Kevan, N. (2011). Understanding the nature and etiology of intimate partner violence and implications for practice and policy. Clinical Psychology Review, 31, 1145-1155. doi: 10.1016/j.cpr.2011.07.001

Dobash, R., Dobash, R., Wilson, M., \& Daly, M. (1992). The myth of sexual symmetry in marital violence. Social Problems, 39, 71-91. doi: 10.2307/3096914

Dobash, R., \& Dobash, R. (2004). Women's violence to men in intimate relationships: Working on a puzzle. British Journal Criminology, 44, 324-349. doi: 10.1093/bjc/azh026

Esquivel-Santoveña, E., Lambert, T., \& Hamel, J. (2013). Partner abuse worldwide. Partner Abuse, 4, 6-75. doi: 10.1891/1946-6560.4.1.6 
Fergusson, D., Horwood, L., \& Ridder, E. (2005). Partner violence and mental health outcomes in a New Zealand birth cohort. Journal of Marriage and Family, 67, 11031119. doi: 10.1111/j.1741-3737.2005.00202.x

Fiebert, M. S. (2014). References examining assaults by women on their spouses or male partners: An annotated bibliography. Sexuality \& Culture, 8, 18-405. doi: $10.1007 / \mathrm{s} 12119-013-9194-1$

Hamberger, K., \& Larsen, S. (2015). Men's and Women's Experience of Intimate Partner Violence: A Review of Ten Years of Comparative Studies in Clinical Samples; Part I. Journal of Family Violence, 30, 699-717. doi: 10.1007/s10896-015-9732-8

Hamby, S. (2016). Self-report measures that do not produce gender parity in intimate partner violence: A multi-study investigation. Psychology of Violence, 6, 323-335. doi:10.1037/a0038207

Hellemans, S., Buysse, A., De Smet, O., \& Wietzker, A. (2014). Intimate Partner Violence in Belgium: Prevalence, Individual Health Outcomes, and Relational Correlates. Psychologica Belgica, 54, 79-96. doi: 10.5334/pb.af

Henning, K., \& Feder, L. (2004). A comparison of men and women arrested for domestic violence: Who presents the greater threat?. Journal of Family Violence, 19, 69-80. doi: 10.1023/B:JOFV.0000019838.01126.7c

Henning, K., Jones, A., \& Holdford, R. (2005). “I didn't do it, but if I did I had a good reason": Minimization, denial, and attributions of blame among male and female domestic violence offenders. Journal of Family Violence, 20, 131-139. doi: $10.1007 / \mathrm{s} 10896-005-3647-8$

Henning, K., Martinsson, R., \& Holdford, R. (2009). Gender differences in risk factors for intimate partner violence recidivism. Journal of Aggression, Maltreatment and Trauma, 18, 623-645. doi: 10.1080/10926770903103248 
Hines, D., \& Douglas, E. (2010). Intimate terrorism by women towards men: Does it exist? Journal of Aggression Conflict and Peace Research, 2, 36-56. doi: 10.5042/jacpr.2010.0335

Hines, D., \& Douglas, E. (2011). Symptoms of posttraumatic stress disorder in men who sustain intimate partner violence: A study of helpseeking and community samples. Psychology of Men \& Masculinity, 12, 112-127. doi: 10.1037/a0022983

Johnson, M. (1995). Patriarchal terrorism and common couple violence: Two forms of violence against women. Journal of Marriage and the Family, 57, 283-294. doi: $10.2307 / 353683$

Krahé, B., Bieneck, S., \& Möller, I. (2005). Understanding Gender and Intimate Partner Violence from an International Perspective. Sex Roles, 52, 807-827. doi: 10.1007/s11199-005-4201-0

Langhinrichsen-Rohling, J., Misra, T., Selwyn, C., \& Rohling, M. (2012a). Rates of bidirectional versus unidirectional intimate partner violence across samples, sexual orientations, and race/ethnicities: A comprehensive review. Partner Abuse, 3, 199230. doi: 10.1891/1946-6560.3.2.199

Langhinrichsen-Rohling, J., McCullars, A., \& Misra, T. (2012b). Motivations for men and women's intimate partner violence perpetration: A comprehensive review. Partner Abuse 3,429-468. doi: 10.1891/1946-6560.3.4.429

Lawrence, E., Oringo, A., \& Brock, R. (2012). The impact of partner abuse on partners. Partner Abuse, 3, 406-428. doi: 10.1891/1946-6560.3.4.406

Lehrner, A., \& Allen, N. (2014). Construct Validity of the Conflict Tactics Scales: A Mixedmethod Investigation of Women's Intimate Partner Violence. Psychology of Violence, 4, 477-490. doi: 10.1037/a0037404 
Lisboa, M., Barroso, Z., Patrício, J., \& Leandro, A. (2009). Violência e género: Inquérito nacional sobre a violência exercida contra mulheres e homens [Violence and gender: National survey about the violence perpetrated against men and women]. Lisboa: Comissão para a cidadania e igualdade de género.

Lövestad, S., \& Krantz, G. (2012). Men's and women's exposure and perpetration of partner violence: An epidemiological study from Sweden. BMC Public Health, 12, 1-10. doi: $10.1186 / 1471-2458-12-945$

Machado, A., \& Matos, M. (2012). Homens de quem não se fala: As vítimas esquecidas da violência na intimidade [Men over which no one speaks: the forgotten victims of intimate partner violence]. Sociedade Portuguesa de Psiquiatria e Psicologia da Justiça, 5, 5-28. Retrieved from http://repositorium.sdum.uminho.pt/bitstream/1822/30893/4/Homens\%20de\%20quem $\% 20 \mathrm{n} \% \mathrm{C} 3 \% \mathrm{~A} 3 \mathrm{o} \% 20 \mathrm{se} \% 20$ fala $\% 20$ Psiquiatria $\% 2 \mathrm{c} \% 20$ Psicologia $\% 20 \% 26 \% 20 \mathrm{Justi}$ \%C3\%A7a_\%202012.pdf

Machado, A., \& Matos, M. (2014). Homens vítimas na intimidade: Análise metodológica dos estudos de prevalência [Male victims of partner violence: Methodological analysis of prevalence studies]. Psicologia \& Sociedade, 26, 726-736. doi: 10.1590/S010271822014000300021

Machado, A., Santos, A., Graham-Kevan, N., \& Matos, M. (2016). Exploring help-seeking experiences of male victims of female perpetrators of IPV. Journal of Family Violence, online first. doi: 10.1007/s10896-016-9853-8

Matos, M., \& Santos, A. (2014). Violência na intimidade: Da gestão do risco à construção da autoria [Intimate violence: From risk management to the construction of authorship]. In M. Matos (Coord.) Vitimas de crime e violência: Práticas de intervenção (pp. 5972). Braga: Psiquilíbrios Edições. 
McCarrick, J., Davis-McCabe, C., \& Hirst-Winthrop, S. (2015). Men's experiences of the criminal justice system following female perpetrated intimate partner violence. Journal of Family Violence, 31, 203-213. doi: 10.1007/s10896-015-9749-z

Moffitt, T., Caspi, A., Rutter, M., \& Silva, P. (2001). Sex differences in antisocial behaviour: Conduct disorder, delinquency, and violence in the Dunedin Longitudinal Study. New York, NY: Cambridge University Press.

Morse, B. (1995). Beyond the conflict tactics scale: Assessing gender differences in partner violence. Violence and Victims, 10, 251-272. doi: 10.1891/0886-6708.10.4.251

Paiva, C., \& Figueiredo, B. (2006). Versão portuguesa das "Escalas de tácticas de conflitos revisadas": Estudo de validação [Portuguese version of "Revised Conflict Tactics Scales": A validation study]. Psicologia: Teoria e Prática, 8(2), 14-39. Retrieved from http://editorarevistas.mackenzie.br/index.php/ptp/article/view/1045/763

Penal Code (2014). DL $n .{ }^{\circ}$ 48/95, March 15 [Portuguese Penal Code]. Retrieved from http://www.pgdlisboa.pt/leis/lei_mostra_articulado.php?nid_109\&tabela_leis

Randle, A., \& Graham, C. (2011). A review of the evidence on the effects of intimate partner violence on men. Psychology of Men \& Masculinity, 12, 97-111. doi: $10.1037 / \mathrm{a} 0021944$

RASI (Relatório Anual de Segurança Interna; 2017). Relatório anual de administração interna [Homeland security annual report 2017]. Lisboa: Ministério de Administração Interna. Retrieved from https://www.portugal.gov.pt/downloadficheiros/ficheiro.aspx?v=9f0d7743-7d45-40f3-8cf2-e448600f3af6

Rhodes, K., Lauderdale, D., He, T., Howes, D., \& Levinson, W. (2002). Between me and the computer: Increased detection of intimate partner violence using a computer questionnaire. Annals of Emergency Medicine, 40, 476-484. doi: 10.1067/mem.2002.127181 
Saunders, D. (2002). Are physical assaults by wives and girlfriends a major social problem? A review of the literature. Violence against Women, 8, 1424-1448. doi: $10.1177 / 107780102237964$

Straus, M., Hamby, S., Boney-McCoy, S., \& Sugarman, D. (1996). The revised conflict tactics scales (CTS2): Development and preliminary psychometric data. Journal of Family Issues, 17, 283-316. doi: 10.1177/019251396017003001

Straus, M. (1999). The controversy over domestic violence by women: A methodological, theoretical, and sociology of science analysis. In X. B. Arriaga \& S. Oskamp (Eds.), Violence in intimate relationships (pp.17-44). Thousand Oaks, CA: Sage.

Straus, M. (2010). Thirty years of denying the evidence on gender symmetry in partner violence: Implications for prevention and treatment. Partner Abuse, 3, 332-363. doi: $10.1891 / 1946-6560.1 \cdot 3.332$

Straus, M. (2012). Blaming the messenger for the bad news about partner violence by women: The methodological, theoretical, and value basis of the purported invalidity of the conflict tactics scales. Behavioral Sciences \& Law, 30, 538-556. doi: $10.1002 / \mathrm{bs} 1.2023$

Swan, S., Gambone, L., Caldwell, J., Sullivan, T., \& Snow, D. (2008). A review of research on women's use of violence with male intimate partners. Violence and Victims, 23, 301-314. doi: 10.1891/0886-6708.23.3.301

Tillyer, M., \& Wright, E. (2014). Intimate partner violence and the victim-offender overlap. Journal of Research in Crime and Delinquency, 51, 29-55. doi: $10.1177 / 0022427813484315$

Tjaden, T., \& Thoennes, N. (2000). Prevalence and consequences of male-to-female and female-to-male intimate partner violence as measured by the national violence 
against women survey. Violence against Women, 6, 142-161. doi: $10.1177 / 10778010022181769$

Tsui, V. (2014). Male victims of intimate partner abuse: Use and helpfulness of services. Social Work, 59, 121-30. doi: 10.1093/sw/swu007

Winstok, Z., \& Straus, M. (2014). Gender differences in the link between intimate partner physical violence and depression. Aggression and Violent Behavior, 19, 91-101. doi: 10.1016/j.avb.2014.01.003

Wood, R., \& Griffiths, M. (2007). Time loss whilst playing video games: Is there a relationship to addictive behaviours? International Journal of Mental Health and Addiction, 5, 141-149. doi: 10.1007/s11469-006-9048-2

Zverina, M., Stam, H., \& Babins-Wagner, R. (2011). Managing victim status in group therapy for men: A discourse analysis. Journal of Interpersonal Violence, 26, 28342855. doi: $10.1177 / 0886260510390949$ 